\title{
Remembranzas de un departamento de Arqueología con los primeros arqueólogos formados en El Salvador
}

Fabricio Valdivieso ${ }^{1}$

La máxima obra propuesta al ser humano

es la de forjarse un destino

Alejo Carpentier

\section{Pretendiendo una introducción}

Supe de un caso, como muchos han de haber, de un empleado que había dedicado treinta y cinco años de trabajo a su institución. En el camino había dejado muchos recuerdos y amigos, quienes en su mayoría hace algún tiempo abandonaron la entidad. Se aproximaba la hora de su retiro. Entre sus compañeros de trabajo, de una generación mucho más joven, aquello no fue más que un sencillo y ligero adiós...

En el interior del viejo archivo del Departamento de Arqueología, entre papeles había un humilde escrito a mano en una corrugada y amarillenta página, el cual decía "este papel que he escondido por aquí es para que recuerden a R. C., quien deja aquí treinta y cinco años de trabajo". Reservaré el nombre de esta persona, solo Dios y el diablo sabrán que ha sido de el, sin embargo su sencillo escrito, a modo de juego, parece haber burlado el tiempo, dentro de cajas que debieron pasear de bodega en bodega, en las diferentes cedes del Departamento de Arqueología por esta ciudad.

Aquello me hace ver en el silencio de muchos un extraño y mudo impulso, como pidiendo al tiempo que sus historias aquí vividas prevalezcan. Lo mis-

\footnotetext{
1 Arqueólogo, Universidad Tecnológica de El Salvador, Utec y Ex Coordinador del Departamento de Arqueología de Concultura, hoy Secretaría de Cultura de la Presidencia.
} 
mo me sucede. No queriendo que el relato de los primeros arqueólogos sea a viva memoria una vivencia de entre mesa, o como un contador de cuentos de salón, y por temor a olvidar este pasaje prefiero escribirlo. Es una remembranza generalizada relacionada a los primeros arqueólogos hechos en El Salvador, en nuestro chiquito país, y qué fue de algunos de ellos hasta el momento de este escrito, y su aporte. Esta es mi versión.

\section{Primera Parte}

Fue en octubre de 2004 cuando dio inicio oficial el nuevo Departamento de Arqueología de la Dirección Nacional de Patrimonio Cultural de CONCULTURA, a propuesta del autor.

La creación de un Departamento de Arqueología se trataba de un proyecto que venía gestándose dos años antes, pretendiendo convertir la entonces Unidad de Arqueología en un ente institucional con mayor libertad de acción, eliminando tramites burocráticos en ocasiones innecesarios, que entorpecían la agilidad de resoluciones inmediatas y ejecución de proyectos. Aquella era una Unidad institucional subyugada por la entonces Coordinación de Investigaciones, esta última dependía de la Dirección Nacional de Patrimonio Cultural. En otras palabras, como ejemplo, al abrirse un caso, éste pasaba por el conocimiento de tres instancias: jefatura de unidad, coordinador de investigaciones y por ultimo el director de patrimonio cultural, y en su caso a Presidencia, de lo cual solamente el jefe de unidad era arqueólogo, los demás aportaban con el criterio institucional, o personal, para la aprobación o denegación de permisos, ejecución de proyectos y otros. La falta de una normativa de regulación de investigaciones arqueológicas, procedimientos y otras acciones no estandarizadas, también tendía a que el jefe de unidad se apegara a su propio criterio, o cambio de criterio, tendiendo a restar continuidad a proyectos de largo plazo, y la no concordancia en el seguimiento dado por los jefes predecesores. A lo anterior se suma la confusión de archivos organizados conforme a la época y criterio de cada jefe, sumado a la carencia de políticas de manejo y otros. Estos problemas fueron detectados, por lo que urgía proponer cambios inmediatos.

Pero lo anterior tiene un precedente, sus raíces nos llevan a la primera mitad del siglo XX, hacia 1928. Fue Antonio Sol con quien surge por vez primera 
un Departamento de Historia en el entonces Museo Nacional "Dr. David J. Guzmán". Las fuentes documentales nos hacen considerar que fue aquel Departamento el primer ente estatal en ocuparse del rubro arqueológico.

Con esta entidad encargada del área de arqueología en el interior de aquella institución, se organizan los primeros depósitos de piezas y materiales. Este museo cargaba así con la oficina de arqueología, el cual se ubicó en diferentes lugares: el museo primero fue fundado en 1883, por el Doctor David J. Guzmán. Antes de instalarse en la ubicación actual en la colonia San Benito en San Salvador, ocupó locales en el antiguo edificio de la Universidad Nacional, en la Finca Modelo y en algunos pabellones de Casa Presidencial, hoy EXCAPRES en San Jacinto. Luego fue trasladado a la colonia San Benito, edificio el cual fue dañado por el terremoto de 1986, demolido hasta el año de 1998. El edificio actual fue terminado en 1999, en donde algunas de sus oficinas fueron ocupadas desde finales de ese mismo año por la entonces Unidad de Arqueología hasta el año 2004. Sin embargo hubo un instante en que la Unidad de Arqueología fue colocada en el edificio de Concultura en el Centro de Gobierno, tal se explicará en otras páginas.

Con el paso del siglo XX esta entidad de arqueología adquiere diversos nombres, lo cual ha quedado evidenciado en viejas cartas, memos y otros documentos que en ocasiones se sellan con el nombre de Departamento de Excavaciones Arqueológicas, Departamento de Arqueología, Sección de Arqueología, o simplemente Área de Arqueología. Aunque mucho de los trabajos arqueológicos realizados en aquella época, documentos de los cuales en su mayoría se encuentran en los viejos archivos del actual Departamento de Arqueología, ninguno deja en claro en qué momento y el porqué cambiaban de nombre. Posiblemente se debía al criterio de cada nuevo director o jefe. De 1948 a 1954 el Departamento de Excavaciones Arqueológicas estuvo a cargo del arqueólogo nortemaricano Stanley H. Boggs. Luego, por poco tiempo, estuvo a cargo de Tomás Fidias Jiménez. Años más adelante, en 1965, la jefatura del entonces llamado Departamento de Arqueología del Museo Nacional, es retomada nuevamente por Boggs hasta 1988. Este Departamento años más tarde dependerá de la Dirección de Patrimonio Cultural.

Según documentos variados, para 1988 aquello que por más de veinte años fue conocido como Departamento de Arqueología se tiene luego como Sección de Arqueología, dirigida por Manuel López, otrora asistente de Stanley H. Boggs. En cuanto a Boggs, durante los últimos años de su vida hasta 1991 
dirigió el registro de la colección del Museo Nacional "Dr. David J. Guzmán”.

Es a la gestión de Boggs a quien se debe la creación de las primeras fichas de registro y establecimiento de la primera ceramoteca estatal. Durante su gestión se adquirieron los sitios, que hoy conocemos como parques arqueológicos, San Andrés, Tazumal y Cihuatán y los primeros museos de sitio. Con Boggs dentro de aquella entidad de arqueología se alcanza una mayor proyección de la arqueología salvadoreña en el mapa científico del mundo, se logran los primeros registros de colecciones privadas, publicaciones y dirección de algunos de los primeros grandes proyectos de investigación estatal incluyendo las primeras clasificaciones cerámicas, entre otros muchos avances. Era a través de aquel Departamento en donde se canalizaba la investigación arqueológica en nuestro país. Entre las más conocidas se citan las investigaciones en Chalchuapa, Quelepa, Santa Leticia, San Andrés, Cara Sucia, valle de Zapotitán dentro del proyecto protoclásico, los reconocimientos y rescates en las áreas de inundación de presas como San Lorenzo y Cerrón Grande, registro de sitios como Asanyamba en el Golfo de Fonseca, y el primer registro de sitios rupestres a nivel nacional, entre otros. Entre sus aportes más importantes se tiene también la creación de fichas de registro de piezas las cuales incluyen fotografías y dibujos. Su gestión también permitió que en 1976 fuesen declarados seis sitios arqueológicos con la nomina de Monumentos Nacionales, los cuales actualmente siguen siendo protegidos por el estado.

En conversación personal con el arqueólogo Paul Amaroli y el historiador Pedro Escalante Arce, me comentan que hace varias décadas existieron algunos intentos de crear una entidad más grande que un Departamento de Arqueología subyugada por una Dirección Nacional de Patrimonio Cultural, es decir, algo así como un instituto. El proyecto más recordado, casi a modo de leyenda urbana, fue durante la administración de Walter Béneke como Ministro de Educación en la segunda mitad de la década de 1960, y con Stanley H. Boggs como jefe del Departamento de Arqueología. En aquel momento se propuso la creación de un Instituto Salvadoreño de Arqueología, el cual entre sus prioridades pretendía detener la destrucción de sitios arqueológicos y el saqueo, y canalizar la información y gestión de manera directa con otras entidades. Se trataba de una institución autónoma. Este proyecto sería patrocinado por algunos filántropos de la época. La discusión era si hacerlo privado o de gobierno, aunque esta historia no queda del todo clara debido a la carencia actual de documentación que detalle aquel caso. Sin embargo, por cuestión de intereses, el 
proyecto fue apagado, mientras en los países vecinos, como Honduras y Guatemala, e incluso México, organismos como éstos corrían otra suerte rumbo a un desarrollo y dinamismo independiente. Lo vemos hoy día con el Instituto Hondureño de Antropología e Historia (IHAH), Instituto Guatemalteco de Arqueología e Historia (IDAEH), y el Instituto Nacional de Antropología e Historia (INAH) de México. Así se tienen modelos de manejo de la arqueología estatal en diversos países latinoamericanos y en el mundo, con entidades autónomas y semi autónomas para la canalización de la arqueología estatal, y facilitador de la misma con otras entidades de gobierno y privadas. De haberse dado un instituto para el manejo de asuntos arqueológicos en nuestro país, Béneke, quien es considerado como uno de los principales protagonistas de la reforma educativa de su época, también hubiese sido recordado como uno de los fundadores de tan importante institución. Pero a pesar que nunca existió una entidad institucional de la magnitud propuesta, la arqueología salvadoreña tuvo su época de oro durante las décadas de 1960 y 1970.

Con la llegada del conflicto armado en El Salvador, en la década de 1980, las investigaciones arqueológicas se suspenden casi en su totalidad. Los proyectos de investigación menguaron y los sitios quedaron a merced de la guerra. No obstante hubo un grupo reducido de arqueólogos extranjeros, como William Fowler y Paul Amaroli, e incluso Stanley H. Boggs y algunos salvadoreños que sostuvieron la arqueología de nuestro país a flote suave, aunque fuera de la geografía arqueológica del mundo. Era de esperar que una guerra apague la investigación arqueológica en campo, y opaque esta actividad reduciéndola al neto trabajo de escritorio y gabinete, mucho de éste enclaustrado entre las paredes del antiguo museo nacional. Aquel momento de los años ochenta fue aprovechado para el registro de material en fichas y publicaciones esporádicas, así como el trabajo de taller de piezas y tratamiento de colecciones.

La arqueología estatal practicada en los años ochenta merece sin duda una remembranza aparte. Parte de este testimonio queda en el viejo archivo del actual Departamento de Arqueología, en correspondencias, memos, algunos informes inmediatos y notas en las que figuran otros autores como Manuel López, Jorge Mejía, y en un fugaz momento Bello Suazo, entre algunos más. Arqueología en épocas de guerra podría ser un tema muy particular a tocar.

Según lo demuestran algunas notas de la época, hubo el intento de sostener la memoria histórica y programas que fortalecieran la identidad cultural durante la convulsiva década, sumado al mantenimiento de los parques arqueológicos 
y museos, inspecciones y excavaciones muy esporádicas. Para 1991, y tras la muerte en aquel año de quien es considerado el pionero de la arqueología moderna de El Salvador, el reconocido Dr. Stanley H. Boggs, ya en ese momento se perfilaba la llegada de cambios.

A la llegada de los años noventa, después de doce años de guerra, el campo de la arqueología se encontraba casi en abandono absoluto, al punto que aquello vendría a ser considerado algo novedoso en este país. Era momento que saliera de su escondite en el museo y romper con el silencio, los años noventa lo dirían.

A principios de aquella década la arqueología salvadoreña giraba a dínamo diferente que los países vecinos. Los logros alcanzados en las décadas anteriores a los ochentas habían quedado engavetados, prácticamente olvidados, en archivos dentro en un atrasado y obsoleto museo.

En vísperas de la firma de los acuerdos de paz en 1992, la arqueología salvadoreña empieza a perfilar una nueva etapa en su historia. Nuestro país recibiría una arqueología sin Boggs, quien dedicó su vida a esta ciencia y cuya obra le recordarían siempre en nuestro país. Empiezan a verse rostros nuevos al mando de este rubro. A su vez, en el país aparecen nuevas escuelas de arqueología, como los japoneses, en un terreno que durante casi todo el siglo XX parecía un campo exclusivo para los norteamericanos. Y luego, en el devenir de la nueva década se dan los arqueólogos salvadoreños tal explicaré más adelante, y algunos nacionales preparados en el extranjero. A los cambios que definen las etapas antes de la guerra y después, se suma en 1991, la creación por decreto de la nueva organización de la administración y rectoría estatal de la cultura y el arte, institución denominada: Consejo Nacional para la Cultura y el Arte Concultura. Se trata de una institución dependencia del Ministerio de Educación, en donde se establecen nuevas jerarquías institucionales y funcionalidad. Esta entidad agrupa todas las instancias que competen en asuntos de cultura y patrimonios, así como proyecciones artísticas estatales, incluyendo Televisión Cultural Educativa, parque Zoológico, Museos y edificios históricos como los teatros nacionales y Palacio, entre otros.

Por su lado, la arqueología empezaba a latir. Fue durante la primera mitad de los noventa en que el sitio arqueológico Joya de Cerén da brotes, haciendo surgir nuevamente ante los ojos de la comunidad internacional, nuestra arqueología. La historia del hallazgo y sus interpretaciones son ampliamente 
conocidas en múltiples publicaciones. Se trata de un sitio localizado a más de cinco metros de profundidad cerca de San Juan Opico, en el valle de Zapotitán, descubierto en 1976 tras la construcción de unos silos para almacenar granos. Aquel hallazgo fue tomado por el Dr. Payson Sheets en 1978, y sus más prolongadas excavaciones inician en 1989, con la excavación total de las primeras estructuras. Los primeros estudios sugieren tratarse de una comunidad del periodo clásico sepultada por la ceniza de un pequeño volcán localizado a no más de un kilómetro del asentamiento. Sus cenizas habían dejado intacto el último capitulo de actividad humana en el área, hace más de 1500 años. Fue así nuestro primer Patrimonio de la Humanidad nominado por la UNESCO en 1993, y la promesa de mayores sorpresas para el futuro, marcando con este sitio una arqueología diferente en el área Centroamericana.

A lo largo de la última década del siglo XX, regresarían las misiones de investigación, aunque aun a baja escala. Los años noventa serían una época de transición entre lo que fue la oscura década de los ochenta y el rebrote de investigaciones arqueológicas durante el 2000, aunque aun faltaría consolidar las excavaciones a gran escala, como las acaecidas en los años cincuenta, sesenta y setenta en Tazumal, San Andrés y Quelepa, y creación de nuevos parques.

Según algunas notas, dentro de esta nueva institución, en un principio se tiene un ente llamado inicialmente Departamento de Arqueología, quizás en memoria a la vieja institución. Luego, a menos de dos años fue llamada Sección de Arqueología y finalmente Unidad de Arqueología. Es posible que la baja demanda de actividad arqueológica en la década de los ochentas fue la causante en aquel tiempo, al momento de la creación de Concultura, en ubicar la parte encargada del área de arqueología en la escala más baja de administración estatal: la entonces Unidad de Arqueología, bajo la Coordinación de Investigaciones, y esta última bajo Dirección Nacional de Patrimonio Cultural. En aquellas profundidades institucionales, por la vía legal era casi imposible llegar a entablar un saludo con la Presidencia de Concultura. A un paso de ser nada, vemos que esto se encontraba muy, pero muy lejos de aquello que en la década de 1960 se pensó fuese un Instituto de Arqueología.

Aquella Unidad, como su nombre lo indica, se limitaba a un arqueólogo jefe y una secretaria, encargados de la administración de siete parques arqueológicos y supervisión de proyectos de investigación a nivel nacional, y hacer cumplir la nueva Ley de Protección al Patrimonio Cultural de El Salvador 
y su Reglamento, creado en 1993, entre otros. Iniciando esta nueva etapa en la historia de la arqueología, luego de la muerte de Stanley H. Boggs, hubo de jefe los arqueólogos Paul Amaroli, Emmanuel Broullette, luego Fabio Esteban Amador, y hasta 1997 José Vicente Genovés de quien más adelante hablaremos.

Hemos de observar que en los años sesentas se tuvo una visión muy a futuro con la propuesta de crear aquel instituto de arqueología. Luego de treinta años, una institución de esta naturaleza, sin duda hubiese manejado procedimientos más consolidados. Para los noventa hasta la actualidad, el Departamento de Arqueología, o cualquier otra instancia de arqueología dentro del gobierno, es y ha sido vulnerable a cambios, e incluso a desaparecer si se dispone, a falta de un decreto que sustente su existencia. Así también, con relación a la posición de esta entidad dentro del organismo gubernamental, ya lo han observado otros, veremos que el criterio técnico tiende a desvalorizarse siempre que existe una instancia superior sobre la entidad de arqueología. Es decir, la Dirección Nacional de Patrimonio Cultural por arriba del Departamento de Arqueología, considerando que esta dirección tendrá siempre la última palabra sobre el criterio de los entendidos en el tema, como los arqueólogos. De este modo, no se ve sentido alguno el dictamen de estos últimos si el de arriba dispondrá avalarlo o no a su propio criterio, teniendo o no preparación académica en este campo. Ya en los años 60's como en la actualidad esta observación sigue siendo latente.

Durante la década de los noventa hubo que lamentar la perdida irreversible de importantes sitios arqueológicos, como Madre Selva, y la alteración de otros como Finca Rosita y Carcagua, y otros que no escapan al vandalismo y el saqueo fuera de control. El trasfondo de ello era debido a la falta de adecuados procedimientos de ley en contra del acelerado desarrollo urbano e industrial del país. Los ires y venires de la arqueología salvadoreña en la primera mitad de los noventas se debía prácticamente, a juicio personal, a ese renacer institucional. A lo anterior se suman las faltantes dejadas por la época de guerra, entre ellos la carencia de personal capacitado, sobretodo arqueólogos salvadoreños, y la falta de criterios consolidados para los procesos que conllevasen a salvar sitios. Y sobre todo, el débil fortalecimiento de esta área mediante leyes y equipo técnico entre otros. Era la antesala de una nueva etapa para la arqueología salvadoreña. 
Se trataba de un arqueólogo para todo el país... no era suficiente. En aquel momento, la figura de este nuevo personaje de gobierno era prácticamente desconocida. Su función o rol social escapaba al entendimiento de muchos ¿Qué hace un arqueólogo?. Aquel personaje era ocupado para muchas cosas, dentro del gobierno debía soportar el peso de la creciente demanda urbanística, atender casos de hallazgos fortuitos y el saqueo desmedido, sumado al mantenimiento de parques e inspecciones de intereses variados, todo a la orden del día. La presión de actividades arqueológicas recaía en esta figura conocida como "el arqueólogo de Concultura". Las políticas de la nueva institución, a diferencia de otros años, exigían a este "súper arqueólogo" abordar todo caso que llevase puesta la palabra "arqueología" y "remoción de suelos", con un respaldo institucional sumamente limitado, a pesar que la arqueología siempre fue medular para la institución. Este arqueólogo debía bien administrar el tiempo y los insumos. Prácticamente su capacidad se distribuía en el papeleo acarreado por la recepción de material, registro inmediato de sitios, resoluciones jurídicas y vivir tramitando permisos e insumos, y va de más mencionarlo: pelear con las empresas constructoras. Porqué no decirlo así, dedicaba cinco minutos en atender un caso mediante el teléfono, diez minutos en registrar un sitio, quince minutos en planificar una inspección, y el resto del día en trámites burocráticos... nada para el estudio propiamente arqueológico. No me cabe duda que debió ser la entidad de arqueología más pequeña y pobre de Latinoamérica, y quizás la más ocupada de asuntos de arqueología con poca ciencia.

Con el devenir de los años, la demanda de asuntos arqueológicos fue subiendo paulatinamente, más y más, a tal punto que en el año de 1997, 23 de junio para ser preciso, la entonces Dirección Nacional de Patrimonio Cultural liderada por la Arq. María Isaura Aráuz y la Presidencia de Concultura, liderada por don Roberto Galicia, optaron por contratar, a medio tiempo, cuatro estudiantes de la nueva carrera de arqueología de la Universidad Tecnológica de El Salvador. Aquella disposición de contratación marcaría el futuro de la arqueología estatal durante los próximos años.

\section{Segunda Parte}

Para aquel momento, la entonces Unidad de Arqueología contaba ya con cuatro nuevos técnicos, una secretaria y un jefe, y posteriormente se agregaría un colaborador administrativo para los parques arqueológicos. Se trataba de Claudia Ramírez, Marlon Escamilla, José Heriberto Erquicia y mi persona. 
Luego se sumarian dos técnicos más: el estudiante Roberto Gallardo y el arqueólogo japonés Shione Shibata, contratado este último como asesor de la Unidad. Shibata fue maestro de universidad de los estudiantes mencionados. Aquella Unidad de Arqueología era dirigida por el arqueólogo salvadoreño José Vicente Genovés, graduado en la Universidad San Carlos de Guatemala.

Estos estudiantes habían pertenecido a la recién creada y luego extinta Universidad San Jorge, en San Salvador. Se trataba de un efímero proyecto que abría las carreras de Antropología, Arqueología e Historia. Para estas tres carreras, solamente existieron estos cinco estudiantes, y curiosamente todos iban para arqueología. Es risible que aquello debió ser por un tiempo la universidad más pequeña del mundo, dentro de la habitación de una casa en la colonia San Benito. La Universidad San Jorge, que inicia actividades con estos cinco estudiantes de arqueología en 1995, desaparece en 1997 tras ser cerrada por la Dirección de Educación Superior del Ministerio de Educación, por carecer de campus apropiado y otros requisitos. El proyecto de formar arqueólogos en nuestro país, a un hilo de caer, en 1997 es retomado por la Universidad Tecnológica de El Salvador, Utec y el proyecto japonés destacado en Casa Blanca desde 1995, dirigido por el profesor Kuniaki Ohi. Para aquel año, tres de los cinco estudiantes estudiante ya habíamos entablado contacto con los encargados del proyecto japonés, bajo la premisa de obtener prácticas de campo. Aquello se transformó en amistad con la misión asiática, sin saber cuan significante sería para su formación profesional y el destino de este rubro. Se tiene así un nuevo pensum creado por arqueólogos japoneses de la Universidad de Estudios Extranjeros de Kyoto, y respaldados por la Utec ante el Ministerio de Educación de nuestro país. Como es de esperar, y debió suceder en la historia de muchas otras carreras, la arqueología salvadoreña nace gracias a la incursión de una entidad extranjera: en este caso fueron los japoneses, quienes fungieron como maestros y asesores de tesis para graduación en el año 2000. Aquellas tesis, al final fueron respaldadas por un jurado evaluador conformado por el profesor arqueólogo Kuniaki Ohi, por el doctor en educación Manuel de Jesús Galdámez, doctor arqueólogo norteamericano William Fowler Jr. y el arqueólogo japonés Shione Shibata. De este modo queda abierta la carrera de arqueología gracias a la visión tenida por la Universidad Tecnológica de El Salvador, cuya primera graduación fue anunciada en los principales medios periodísticos de nuestro país. Pero veamos como llegamos a este punto. 


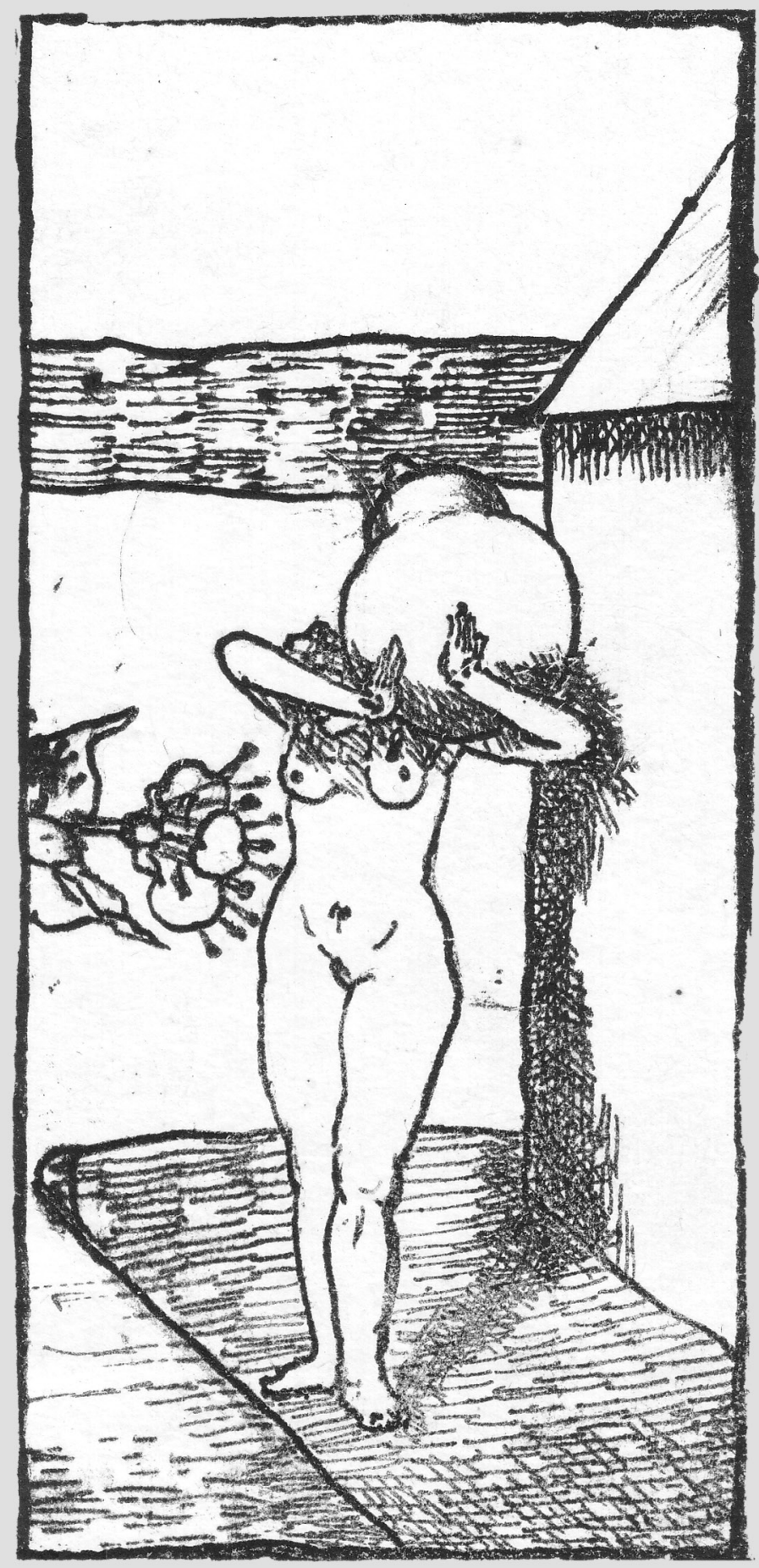

$$
\frac{\text { IVAN }}{\text { NAVARREJE }}
$$


Volviendo a la vida estudiantil, en nuestra rutina de estudio y laboral se recibían clases de jueves a sábado, y se trabaja en Concultura de lunes a miércoles. Era aquella la formación de la primera generación de arqueólogos salvadoreños hechos en El Salvador. Por su lado, en el ambiente de trabajo, bajo la jefatura de Genovés, los estudiantes inician sus nuevas inspecciones arqueológicas en terrenos propensos a construcción, emitiendo así resoluciones respaldadas por el Departamento Jurídico de Concultura y la Dirección Nacional de Patrimonio Cultural, dirigida por la Arq. Arauz.

Las inspecciones se daban casi a diario, era algo que se tornaría después en un estilo de vida. Luego iniciaron los sondeos, rescates y salvamentos arqueológicos, uno tras otro, en construcción de carreteras, lotificación de fincas, restauración de inmuebles históricos tal es como iglesias y edificios públicos, rescates en predios baldíos y zonas urbanas, hasta en la arena de la propia costa, o inclusive en el jardín de la casa de alguien. No exageramos cuando decimos en todo lugar. Paulatinamente los cinco estudiantes empezaron a dirigir proyectos arqueológicos, registrar suelos y rasgos, dibujar materiales y a emitir los primeros informes técnicos, haciéndose poco a poco de experiencia y perfeccionando el trabajo. Con el tiempo y la práctica intensiva fueron reconociendo suelos y tipologías cerámicas, entrelazándola con la parte teórica. Fueron tantos proyectos que solamente mi persona, a mis actuales 33 años, tiene en su currículo más de cincuenta proyectos de excavación arqueológica de toda índole en su haber, ya sea como director o como participante, así como supervisor.

En un principio la asesoría de los técnicos de la entonces Unidad de Arqueología estuvo a cargo de los arqueólogos japoneses y de nuestro jefe José Vicente Genovés, y en ocasiones nos echaban la mano otros arqueólogos como Paul Amaroli por un lado, y William Fowler por el otro, compartiendo sus conocimientos. Luego el circulo de contactos de investigadores fue subiendo, incorporándose franceses, mexicanos, entre ellos Luís Alberto Martos, director del Departamento de Arqueología del INAH en México, guatemaltecos, franceses, norteamericanos y muchos más, hasta la actualidad. La recepción de todos ellos se daba a través de la Unidad de Arqueología.

Los cuatro estudiantes-técnicos de aquella época se repartían el trabajo, y con ello se multiplicaba el estudio, el uno aprendía del otro, por lo menos así lo percibió mi persona. En un principio, algo he mencionado en párrafos anteriores, hacia 1997 se contaba únicamente con una oficina en una esquina 
del segundo nivel del edificio ocupado por Concultura, en el Plan Maestro del Centro de Gobierno en San Salvador. Dentro de aquella oficina se tenía un área de recepción ocupada por la secretaria, el escritorio del jefe junto a una vieja maquina de escribir y un mueble de madera de pino con seis gavetas y dos compartimientos en donde se guardaban fotos, informes y libros e insumos de papelería, adjunto a una rústica planera. Y luego viene una solitaria y amplia mesa de madera para los cuatro estudiantes técnicos. Nuestro mundo de labores giraría alrededor de aquella mesa por los próximos tres años. Parte del mobiliario creemos perteneció a la antigua oficina ocupada por "mítico" Stanley H. Boggs en sus dorados tiempo, muchos años atrás. Luego se agregó un escritorio al quinto estudiante técnico, Roberto Gallardo, quien unos meses después de la contratación de los primeros estudiantes se adjunto al equipo.

Aquella oficina carecía de depósitos de materiales y transporte para realizar los proyectos e inspecciones, el cual muchas veces era proporcionado de manera voluntaria por los nuevos técnicos. Se sumaba también la carencia de computadoras. Todo ello conformaba una bola de insuficiencia de insumos para trabajar la arqueología. Nadie en aquella oficina tenía un puesto asignado, de tal modo que en aquella única mesa de madera se llegó al punto de pelear puesto, es decir, el que llegase primero por las mañanas tomaría el mejor espacio. Los materiales recuperados de excavaciones arqueológicas y recolección en superficie eran colocados dentro de sus bolsas ordenadas bajo la mesa, haciéndose más y más, constituyendo aquello una especie de cáncer creciente en la reducida oficina de gobierno. El inevitable desorden paulatinamente se hacía cada vez más notorio.

El material arqueológico era lavado en los baños del edificio, y lo secábamos en los pasillos. El material extendido en aquel suelo captaba el interés de muchos, de lo que curiosamente nunca se recibió queja alguna por esta inusual y necesaria actividad. En muchas ocasiones, como contradiciendo la norma laboral, en aquellas oficinas había que entrar en pantalones cortos, chalecos, sombreros o gorras y mochilas, cargados de equipo de campo en un lugar donde se suele andar de regular a formalmente vestido, arrastrando lodo por el piso brillante, y la mirada de todos. Curiosamente en tres años de nuestra presencia por aquel edificio, tampoco hubo queja u observación negativa a nuestro trabajo.

En aquel momento, el seguimiento a lo establecido por los arqueólogos de las décadas anteriores era prácticamente ignorado, debido en gran parte a que los 
protagonistas, en su mayoría habían desaparecido, mientras la documentación se encontraba totalmente escondida en las viejas instalaciones del antiguo museo nacional, empaquetadas. En otras palabras, no hubo quien transmitiera el conocimiento para un seguimiento, era como empezar a crear nuevamente una rama de la arqueología en el país. Es curioso que algunos de los procedimientos que aplicábamos concordaban con prácticas antiguas, cosa que notamos años después al destapar y leer antiguas notas. Aunque el viejo fichero de sitios y planos, sumado a los expedientes de algunos arqueólogos, informes inéditos y libros aun continuaban en manos de aquella Unidad de Arqueología en el interior del viejo y rústico gavetero de madera y planera que en líneas anteriores he hecho mención. Con los años, estos documentos fueron digitalizados y traspasados a bases de datos y consolidar una biblioteca que facilitara la investigación. Había que revolver papeles para reconocer aquel campo olvidado, lo cual no se hizo hasta tener un local más estable en Casa de las Academias en el año 2006, casi diez años después de nuestro primer encuentro con Concultura.

Mientras tanto, en 1997, con José Vicente Genovés se creó un procedimiento para realizar proyectos sin depender de insumos estatales. Aquellos prácticos procedimientos le llamábamos "arqueología pobre". No se utilizaba estación total como en el proyecto japonés, no más que brújulas y cintas, sin computadora, no más que maquina de escribir y calculadora, sin consolidantes como el T.O.T., ni mascarillas, no más que Resistol en agua y un pañuelo, con poco transporte del gobierno no más que condicionado a los autobuses colectivos o vehículos particulares. En fin, la semana arqueológica de lunes a miércoles con "arqueología pobre" variaba a las actividades de estudiante de jueves a sábado en Casa Blanca, con arqueología al modelo japonés, con alta tecnología. Eran dos rostros diferentes de la misma ciencia.

En la Unidad de Arqueología, el procedimiento para realizar inspecciones e investigaciones de sondeo y rescate fue de la manera siguiente, misma que actualmente se sigue: todo insumo, incluyendo transporte, papelería, hasta levantamientos topográficos, trabajadores y en ocasiones hospedaje, les era pedido a los interesados en realizar la obra, con el objeto de apresurar su trámite. Desde un clavo, papel y pita, hasta cien pozos de sondeo eran costeados por los encargados de los proyectos, nada por el gobierno. La solicitud de inspección entraba a la Unidad de Arqueología o a la Dirección Nacional de Patrimonio Cultural, para la cual pedíamos adjuntar mapa de proyecto y topográfico. En la solicitud como mínimo se pedía incluir contactos, responsables 
del proyecto, área y ubicación. Luego de entrada la solicitud, nos poníamos en contacto con los responsables, hacíamos la inspección que consistiría en un recorrido, recolección de materiales en superficie y localización de los mismos, identificación de montículos y potencialidades arqueológicas. A su vez se investigaba en fuentes bibliográficas los antecedentes y se resolvía, ya sea delimitar áreas de protección incluyendo un espacio de amortiguamiento, liberar totalmente el terreno o proceder con un sondeo o rescate para nuevamente resolver. Esta información serviría para remitirla posteriormente, como dictamen técnico, a la Dirección Nacional de Patrimonio Cultural y canalizarla para realizar resolución jurídica.

Con el tiempo los procedimientos fueron perfeccionándose, lo cual quedó establecido en la creación del programa "Ventanilla Única" con el Viceministerio de Vivienda, y las inspecciones de oficio, así como en la Normativa de Regulación de Investigaciones Arqueológicas en El Salvador, en donde se incluirían términos de referencia dictaminados por el Departamento de Arqueología para el desarrollo de investigaciones. Años más adelante resultaríamos muy pocos arqueólogos para realizar tantos estudios a nivel nacional. Con los años esta rutina llevó a la planificaron e innovación de estrategias de contratación de arqueólogos consultores, bajo supervisión estatal, optimizando trabajo y proceder a ocuparnos de otras áreas.

Crear aquello no era del todo fácil pues había que adaptarlo a la realidad del momento y consolidarlo a otros mecanismos, como la otrora inexistente Normativa de Regulación de Investigaciones Arqueológicas para nuestro país, sumado a la formulación de criterios para la creación de términos de referencia, lineamientos de supervisión y otros. Se tenía que comprender toda aquella atmósfera para crear verdaderas estrategias de manejo, tal se dio años después. Con el tiempo hubo lugar para la activación de proyectos propiamente arqueológicos desarrollados por una entidad gubernamental, es decir, estudios de artefactos y rasgos, investigaciones en las estructuras de los parques arqueológicos, el arte rupestre, proyecto Atlas, subacuatico y otros. Habría que preparar nuevamente el campo de acción para una arqueología moderna, y recuperar el tiempo perdido en los años 80`s.

Pero volviendo a la época, el salario tanto del jefe como de los técnicos era mínimo, por muchos años, pero el entusiasmo y los conocimientos venían en letras mayúsculas. Nos encontrábamos realizando verdaderas excavaciones arqueológicas, recursos por los cuales logramos sacar nuestras tesis de gra- 
duación y llenar currículo, y más allá, crear normativas y propuestas que a futuro consolidaría la arqueología de un Departamento moderno. Con aquellas prácticas teníamos muy pronto problemas reales, responsabilidades reales, y tocábamos un mundo que la universidad no enseñaba, incluso ignoraba. Nos acercamos al trabajo con la gente, la convivencia y el servicio social. Era lo real en la vida de estudiante, se nos exigía dirigir, dar observaciones en espacios donde posiblemente no las había, empezábamos a ver con mucha claridad lo que venía. Aquello fue la mejor escuela de arqueología que hemos de haber experimentado y tenido. Empezábamos paulatinamente a diferenciar suelos, épocas de ocupación, estilos y tipos cerámicos, patrones de asentamiento y actividad, entrenar la vista para el reconocimiento de sitios y material en superficie y estratigrafías. En ocasiones sin excavar aprendíamos hablar de épocas de un determinado sitio observado en campo conforme al patrón de asentamiento y cerámica en superficie. Aprendimos el control y ordenamiento del material como quien maneja un vehiculo, y en fin, cada día era una lección. A medida que pasaban los días, los meses y los años, la infinita escuela siempre estuvo ahí, en esa oficina, hasta el momento en que redacto el presente texto.

Entre aquellas actividades en la entonces Unidad de Arqueología también se daba asistencia y supervisión a proyectos de investigación realizados por otros arqueólogos no gubernamentales, a quienes había que revisarles las propuestas y dar seguimiento. En ocasiones hubo que colaborarles en calidad de estudiante y a la vez miembro de Concultura, con levantamientos topográficos, excavación y dibujo. Todo ello se acumulaba en pro del aprendizaje y formación de quienes seríamos los futuros arqueólogos. Hubo que idear un nuevo orden de expedientes y sistema de archivo, e iniciar el control de actividades arqueológicas y registro de las mismas a nivel nacional, sumado al manejo de la información de cada caso y todo el conjunto de casos. Lo anterior se integra a otros expedientes, como el manejo, organización y almacenamiento de materiales acaecidos en cada investigación. Con los años, aquel depósito bajo la mesa se convirtió en un verdadero depósito de materiales, organizado en jabas plásticas y ordenados en una habitación segura, bajo criterios serios de almacenamiento.

Así también se llevaba de lado la administración de los parques y supervisión de O.N.G.s, por lo tanto había que realizar inspecciones periódicas a todos los parques y sitios nacionales: Cara Sucia, Casa Blanca, Tazumal, San Andrés, Joya de Cerén, Cihuatán y Gruta del Espíritu Santo, y luego se agregaría Ciu- 
dad Vieja. Se llevaban carretillas, maquinas cortadoras, abono para plantas y veneno para la maleza, cumas, machetes y afiladores, hasta los talonarios del seguro social para los empleados de parques, entre mil cosas más. Se tenían otras instancias a quienes había que supervisar y proporcionar asistencia, en ocasiones capacitación: consultores, organizadores de planes de manejo, trabajo de alcaldías y casa de la cultura, universidades y escuelas, fundaciones, entre otros. Así era la vida como empleado de gobierno en el área de arqueología. Como capítulos opuestos, no faltaron ocasiones en que formaríamos parte de operativos junto a la Policía Nacional Civil, INTERPOL y Fiscalía, en allanamientos y cateos, o seguimiento de saqueos, así como peritos. No olvidare que en una de aquellas experiencias, Marlon Escamilla y mi persona, enviados por nuestra institución a inspeccionar un saqueo en Tecpan, La Libertad, nos enfrentamos accidental ante los saqueadores en plena actividad, a quienes en ciego acto fotografiamos, decomisamos el material e inclusive logramos que taparan nuevamente los agujeros excavados y echaran a correr. Saldría de esto una anécdota tras otra, sin embargo personalizaríamos mucho el presente texto.

Pero volviendo a la vida de estudiante de finales de la década de 1990, los días jueves a sábado, tal se ha dicho fueron dedicados al trabajo de estudios, con un horario de 7:30 a.m. a 3:30 p.m. dedicado a la actividad de campo y practicas con el proyecto japonés destacado en el parque arqueológico Casa Blanca. Por las noches, de 7:30 a 11:00, en ocasiones extendidos hasta la madrugada, la misión japonesa nos impartía clases teóricas sobre arqueología, apegados a su pensum. De 1995 a 2000, aquel proyecto fue dirigido por el profesor Kuniaki Ohi, de la Universidad de Estudios Extranjeros de Kyoto, y patrocinado por el Museo de Tabaco y Sal de Japón. Esta remembranza quedo escrita por el profesor Ohi en el informe final de Chalchuapa del año 2000 publicada en Kyoto, Japón. De este modo, en la formación de los futuros arqueólogos participaron más de una decena de arqueólogos japoneses, entre estudiantes y profesionales agregándose otros profesionales en antropología, vulcanología e historia. De este modo la semana se dividía en estudio universitario y trabajo practico con el gobierno, dedicado ampliamente a la arqueología, durante cinco años hasta la graduación de los primeros arqueólogos en noviembre del año 2000.

Para principios de 2001, iniciando el primer año como arqueólogos se vinieron dos terremotos. Irónicamente la arqueología sacó mucha ventaja de aquel siniestro, pues a consecuencia hubo que demoler y en ocasiones restaurar 
edificios históricos, más que todo, las iglesias. Aquellos trabajos por ende tocarían el subsuelo de los templos y edificios. Fue así como inicia la inclusión de la actividad arqueológica en las intervenciones de edificios, logrando la exploración de un nuevo campo para la arqueología: arqueología urbana o lo que llamaremos arqueología en las iglesias. Aunque esta área ya había sido explorada por Amaroli en los años ochentas, y Fowler en los noventa.

Dentro de la arqueología salvadoreña se tienen muchas vertientes que por lo menos tendrían un pequeño precedente. En nuestro país, a poco más de cien años de arqueología, casi todo campo ha sido ya practicado, y aunque no se han desarrollado como se espera, los precedentes ahí están en los viejos archivos y en la memoria de algunos. El único precedente seguro se dictaría con la incursión de nuevas tecnologías para investigación arqueológica, que con los años se dirá.

En los años subsiguientes, los arqueólogos salvadoreños Roberto Gallardo, en el 2000 al 2002, y posteriormente Fabricio Valdivieso, 2002 hasta 2008, se convierten en los nuevos jefes de la Unidad de Arqueología, constituyendo así ya diez años de experiencia en el rubro, y doce de convivir con la arqueología salvadoreña. Hoy día José Heriberto Erquicia, después de varios años como miembro de la Unidad y posterior Departamento de Arqueología, dirige la facultad de Humanidades de la Universidad Tecnológica de El Salvador, en su persona recae la responsabilidad de formar la carrera de arqueología, antropología e historia, por ende la nueva generación de arqueólogos de El Salvador; mientras Claudia Ramírez estudia maestría en restauración en Japón, Roberto Gallardo dirige la sección de investigaciones en el Museo Nacional de Antropología "Dr. David J. Guzmán". Marlon Escamilla, después de permanecer como arqueólogo en el actual Departamento de Arqueología de Concultura, dirigiendo proyectos como Arqueología Subacuatica y Arte Rupestre de El Salvador, ha representado al país en el extranjero, y catedrático y asesor de la carrera de arqueología en la Universidad Tecnológica de El Salvador, entre otros, es becado con fullbright para estudiar maestría en los Estados Unidos.

Durante la administración de Fabricio Valdivieso, mi persona, las propuestas de la nueva organización para el desarrollo de la arqueología entran en acción. Se crea así el Departamento de Arqueología, ascendiendo esta instancia en la escala jerárquica, directamente bajo la Dirección Nacional de Patrimonio Cultural, tal había quedado en tiempos de Stanley H. Boggs. Este Departamento se equipa con una donación de insumos para investigación, que en el 
año 2000 fue proporcionada por el gobierno de Japón, en la cual se incluyen planchetas, brújulas, teodolitos, ojos de nivel, equipo para el dibujo, cámaras fotográficas y revelado, mesas de trabajo, cajas plásticas, reglas, calibradores, perfílelas, y mucho más. Aprovechando mi calidad de autor, y otorgando estos apuntes para que las generaciones futuras continuidad y desarrollo al esfuerzo realizado por el equipo de primeros arqueólogos, no puedo dejar de decir cual ha sido nuestro trabajo en los últimos cinco años. Con esta jefatura se activa el programa "Ventanilla Única", y se inicia el trabajo formal mediante consultorías de arqueología, estableciéndose así procedimientos oficiales. También se crea la Normativa de Regulación de Investigaciones Arqueológicas, un mapa digital de sitios, se elaboran las primeras bases de datos, rotulación vial de sitios arqueológicos, programa de sesiones, conferencias y talleres, se organiza el archivo, biblioteca y depósitos, se estandarizan procedimientos para el accionar de arqueología, se involucran las universidades en la vida académica del Departamento, se fortalece el criterio de conservación y salvaguarda de sitios arqueológicos, se gestiona nuevo equipo y local para el Departamento de Arqueología, y se encamina hacia la creación de una instancia moderna para el manejo de la arqueología estatal. A su vez se da un giro en la difusión de la arqueología salvadoreña fortaleciendo el trabajo con los medios escritos y televisivos, se inicia la creación del diseño de una página web, se hacen participes los estudiantes, se da apertura a proyectos arqueológicos novedosos dirigidos por el Departamento como lo es Arte Rupestre y Arqueología Subacuatica, Deconstrucción Arqueológica en Tazumal, Ventanas Arqueológicas y Arqueología Urbana. Se inicia el trabajo intensivo en la región norte del país, y el golfo de Fonseca, se desarrolla el proyecto Atlas y se proponen 77 sitios para que fuesen declarados Monumentos Nacionales lo cual quedó a nivel de propuestas. Asimismo se redactan las primeras compilaciones de informes técnicos y se enriquecen las bibliotecas nacionales con la remisión de informes y textos producidos por los investigadores activos en El Salvador, el trabajo con filatelia, entre otros alcances, como la redacción de esta primera remembranza.

Para el 2004, la demanda de actividades arqueológicas se incrementa, con la creación del programa "Ventanilla Única" y el seguimiento a la creciente de proyectos de investigación arqueológica y construcciones privadas a nivel nacional, en cumplimiento a la Ley, entre muchas más. De este modo se propuso la contratación de mayor número de personal, y se integran actividades con arqueólogos voluntarios enviados por la Agencia Internacional de 
Cooperación de Japón (JICA), quienes son coordinados por el Departamento de Arqueología. Por otro lado se gestiona la ubicación permanente del nuevo Departamento de Arqueología, el cual como Unidad de Arqueología, había pasado por varias cedes: antiguo Museo Nacional "David J. Guzmán” (desde 1991 hasta 1996), oficinas de Concultura en el Plan Maestro del Centro de Gobierno (1996-1999), luego en el nuevo edificio del Museo Nacional de Antropología “Dr. David J. Guzmán” (1999 - 2004), Ex Casa presidencial en el barrio San Jacinto (2004 - 2006) y finalmente en Casa de las Academias, con el apoyo de la Academia Salvadoreña de la Historia, dirigida esta última por el Lic. Pedro Escalante Arce. En este último local se tiene finalmente un espacio para el área administrativa, gabinete y laboratorio, depósito y biblioteca, despensa, computadoras y mesas de trabajo entre otros.

La realidad actual en el Departamento de Arqueología, aunque se pretenda ganar más, dista mucho de aquella época de estudiantes de finales de 1990. El cambio se debe en gran medida a la exitosa unidad del grupo, el respeto a las ideas de cada quien, el consenso y el apoyo moral le daba mucha ventaja al proyecto de creación de arqueólogos salvadoreños, quienes manejarían luego la arqueología de este país. Nuevamente esta realidad dista en gran medida de lo que encontramos en aquellos primeros años, gracias a la visión de quienes en aquel 1997 nos contrataron y guiaron, sumado a las disposiciones de los amigos japoneses bajo la dirección de Kuniaki Ohi y Shione Shibata, por enseñarnos, y la visión de la Universidad Tecnológica de El Salvador tenida hacia el proyecto de crear arqueología sostenible en nuestro país. El desarrollo de esta área debe mucho al trabajo en equipo y la experiencia e iniciativas personales por sacar adelante una carrera que en aquel tiempo nadie aparentemente daba un centavo, y mucho se alejaba del estimulo para hacer vida de ello. Se añade así el invaluable apoyo dado por la Academia Salvadoreña de la Historia, y en especial a la gestión del investigador salvadoreño Lic. Padro Escalante Arce, y su carisma con la nueva generación, así como el apoyo otorgado por el Dr. Ramón Rivas al desarrollo de la antropología y arqueología en la referida universidad, y a los primeros profesionales de esta rama.

Al momento de asumir nuestro rol como arqueólogos en la segunda mitad de los noventa, recibíamos un país pobre en la idea de la arqueología como una ciencia para el desarrollo. La figura de un arqueólogo era una verdadera novedad, y su labor era desconocida, tan inusual como la misma palabra arqueología. Era tanto trabajo por hacer, una demanda que con los años empezaría a subir gradualmente, mientras descubríamos la existencia de tantos sitios 
arqueológicos en un terreno poco explorado, en donde no mucho se hablaba del tema. Se rompía el hielo y se habría brecha en un territorio desconocido. Aquellos estudiantes, hoy arqueólogos, han llevado la arqueología salvadoreña a ponencias en todo el país, y a importantes congresos y simposios fuera del mismo, y publicando, incluso en importantes revistas como Archaeology Magazine, memorias y páginas en Internet, y cuyas tesis e informes algunos se encuentran en bibliotecas en Universidades en Estados Unidos, México, Centro América e incluso en Japón. Se logró la apertura de espacios en los principales medios de prensa televisivo y escrito, incluso ocupando en ocasiones el encabezado. Lo más importante, se han logrado salvar más de una treintena de sitios arqueológicos, y un número mayor se han aportado a la lista de sitios nuevos descubiertos.

\section{Reflexiones finales}

Existe una moraleja en todo esto. Hemos de ver que desde el inicio de la arqueología en nuestro país, allá por la segunda mitad del siglo XIX, desde el arribo de Efraín Squier hasta la consolidación de espacios para el desarrollo de esta área, se denota que siempre a lo largo del último siglo existió un interés por crear ciencia y conocer nuestra pasado mediante la observación a los restos materiales. Esta admiración hacia nuestras culturas muertas siempre se ha develado, el problema ha sido la sostenibilidad y fortalecimiento de instancias para regular el manejo de estos recursos, el cual se ha visto muchas veces entrelazado con otros intereses. Durante los años cincuenta, sesenta y setentas la arqueología vivió una gran época, adversa a los oscuros años ochenta, conduciendo el tema casi al olvido. Me atreveré a decir que hablar de arqueología era algo fantasioso. Sin embargo, hubo quienes nunca abandonaron el tópico, y creían en su evolución dentro de una sociedad que ciegamente casi extingue el tópico.

Nosotros, los primeros cinco arqueólogos formados en El Salvador, entre la multitud, habremos sido cinco de muchas personas interesadas en el área, con la diferencia que nosotros habríamos estado parados en el lugar correcto en el momento exacto. La misión de japoneses, sumado a la necesidad de arqueólogos en la nueva institución y el pequeño lapsus de existencia de aquella Universidad San Jorge en donde solo hubo una inscripción durante el mes de febrero de 1995, y una apertura de estudios solo acatada por cinco jóvenes, fue como haber atendido un importante turno. Lo que vimos fue un campo árido, como quien busca estudio de algo en donde no existe y había que hacer- 
lo existir. Ese fue nuestro reservado capítulo después de los ochenta. Afortunadamente encontramos una oportunidad en un país con mucho espacio para trabajar, y encaminar una especie de brecha perdida.

Los interesados en nuestra arqueología están ahí, y son muchos, es toda la sociedad. Es un tema que se lleva desde un campesino que mitifica el hallazgo de un sencillo grabado en roca tras su milpa, hasta un intelectual ufanándose de sus conocimientos sobre numeración maya quizás en el bar de un gran hotel. Y el gran reconocido empresario que piensa su próxima vacación en la lejana Grecia o pensar en una foto frente al Foro Romano. La historia y la arqueología están ahí, mientras la sed de cultura crece con el avance difundista venido de importantes fuentes de comunicación masiva como revistas, digamos National Geographic y Arqueología Mexicana, y televisión por cable, como el History y el Discovery Channel, casi formando parte de nuestro diario vivir. Aquello se adversa a nuestra vieja Televisión Cultural Educativa y Colección Tazumal del área básica de nuestro Ministerio. No cabe duda que nuestra arqueología es una oportunidad para nuestro país. Sumaremos otras áreas que merecen su remembranza, como la Historia, la Antropología y la Paleontología, mientras el Estado les debe un más digno espacio.

Quien diría que un día la antropología en nuestro pequeño país pudiese practicarse como una ciencia para el beneficio de las mayorías, o como los ojos de un gobernante que mediante la misma conociese las necesidades de su gente, utilizada como un microscopio social que registra el comportamiento colectivo, y cuyos resultados permitirían la formulación de leyes exclusivas a la realidad de su pueblo, y mecanismos apropiados de un gobierno que utiliza ciencia. Diera así por crearse un Departamento de Antropología de interés estatal. O qué diremos de la Historia, como un área del gobierno que canalice el registro de la experiencia colectiva, y esta información fuese objeto constante de investigación. Con ello comprender nuestro ahora, en aras de la educación, y la previsión, y porqué no decirlo, la predicción. Son disciplinas de interés social las cuales aun presentan un horizonte llano carente de caminos claros, no más que los esfuerzos de grupos independientes fuera de las instancias de gobierno, como la Academia Salvadoreña de la Historia o la Asociación Salvadoreña de Antropólogos, cuyo aporte un día sin duda pasaran al plano del reconocimiento.

Por nuestro lado, aunque la creación de arqueólogos en El Salvador y el crecimiento de un Departamento de Arqueología muestre de modo sustancial 
algunos avances relativos a los años que prosiguieron a la década de 1980, su situación aun atraviesa obstáculos que le impiden alcanzar objetivos mayores, como lo es el rescate de identidades o el crecimiento turístico mediante la proyección de su legado cultural, así como el poseer una ciencia de alto nivel tecnológico y capacidad investigativa que posicionen nuestro país en el ojo internacional, y hacer uso del mensaje que el estudio arqueológico remite. En otras palabras, explotar el recurso arqueológico a su máxima capacidad, como una importante alternativa para el beneficio social. Lo anterior solo lo dan los altos presupuestos y un considerable número de profesionales en el rubro, con mecanismos legales que le sustenten y estimulen su desarrollo.

La presente remembranza debió escribirse como una historia de paso, como quien no pretende dejar sin palabras la anécdota. No era de conformarse con escuchar el relato de lo que un día fue tras la vívida memoria de alguien. Eso sería un recuerdo que condenaría lo sucedido a su extinción, quizás luego de jubilarnos en el seno de una nueva generación de empleados dentro de las futuras oficinas de gobierno. Como lo hizo un día R. C. al esconder su pequeña constancia, es posible que a nuestro modo estemos repitiendo lo mismo entre papeles de arqueología.

Las intenciones de este escrito irán más allá del hecho de compartir una anécdota tras una crítica moderada, si desea verse así. Este relato aborda otras dimensiones, entre las más importantes, sus letras esconden un llamado a la continuidad de este esfuerzo por crear ciencia en nuestro país. Pero más importante aun, el alma de esta remembranza, es en verdad un pasaje vertebral en la historia de nuestra arqueología. 


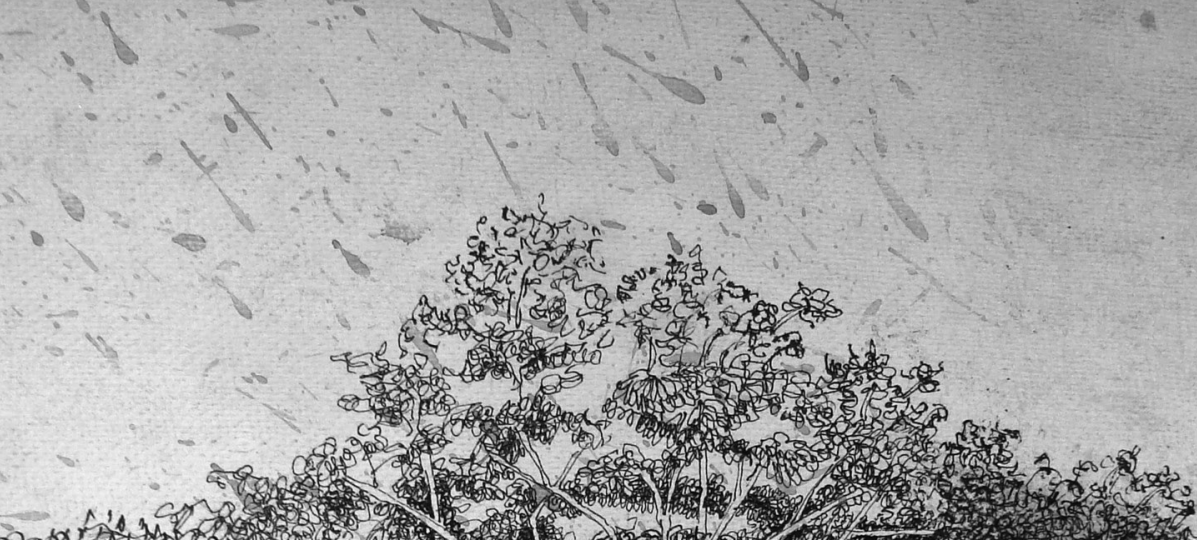

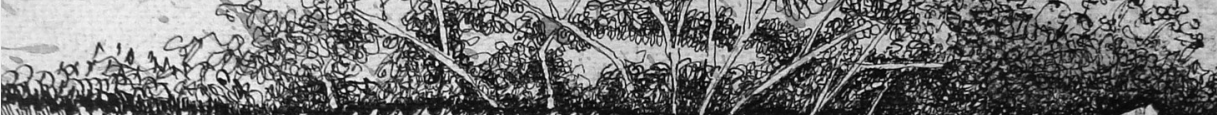
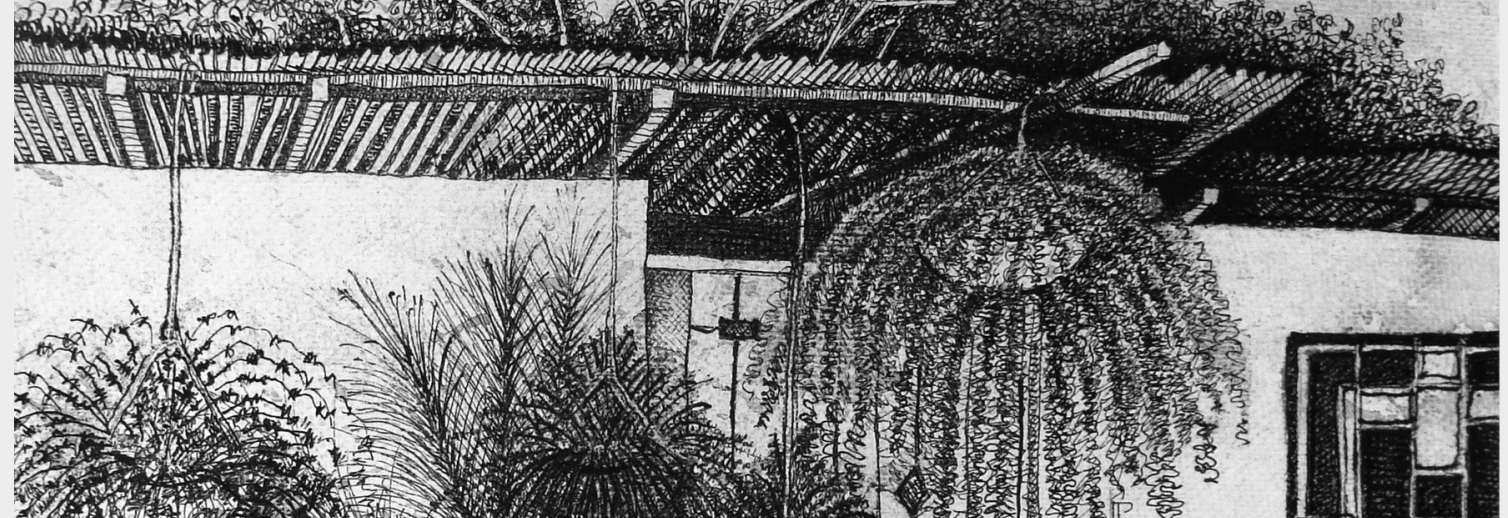

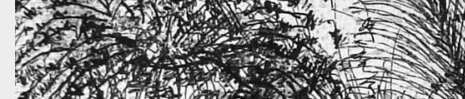

3

trent

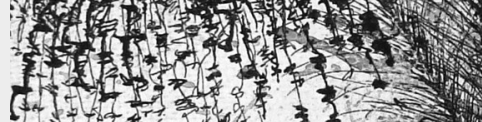

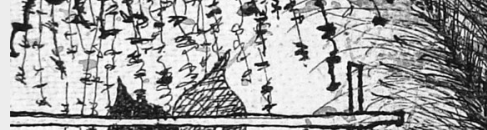

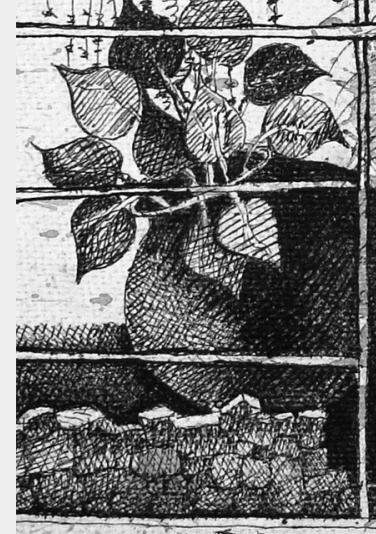

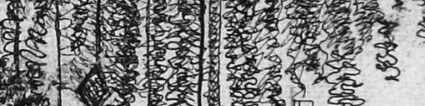

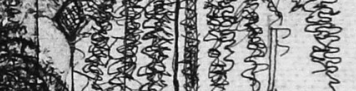
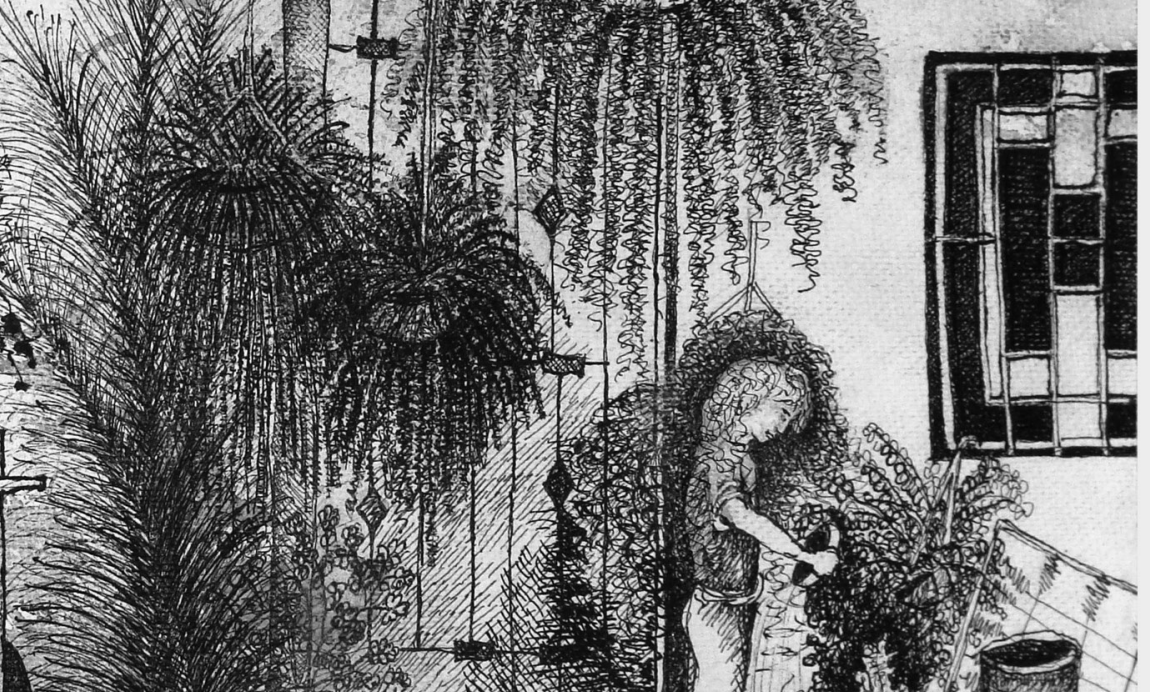

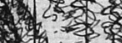
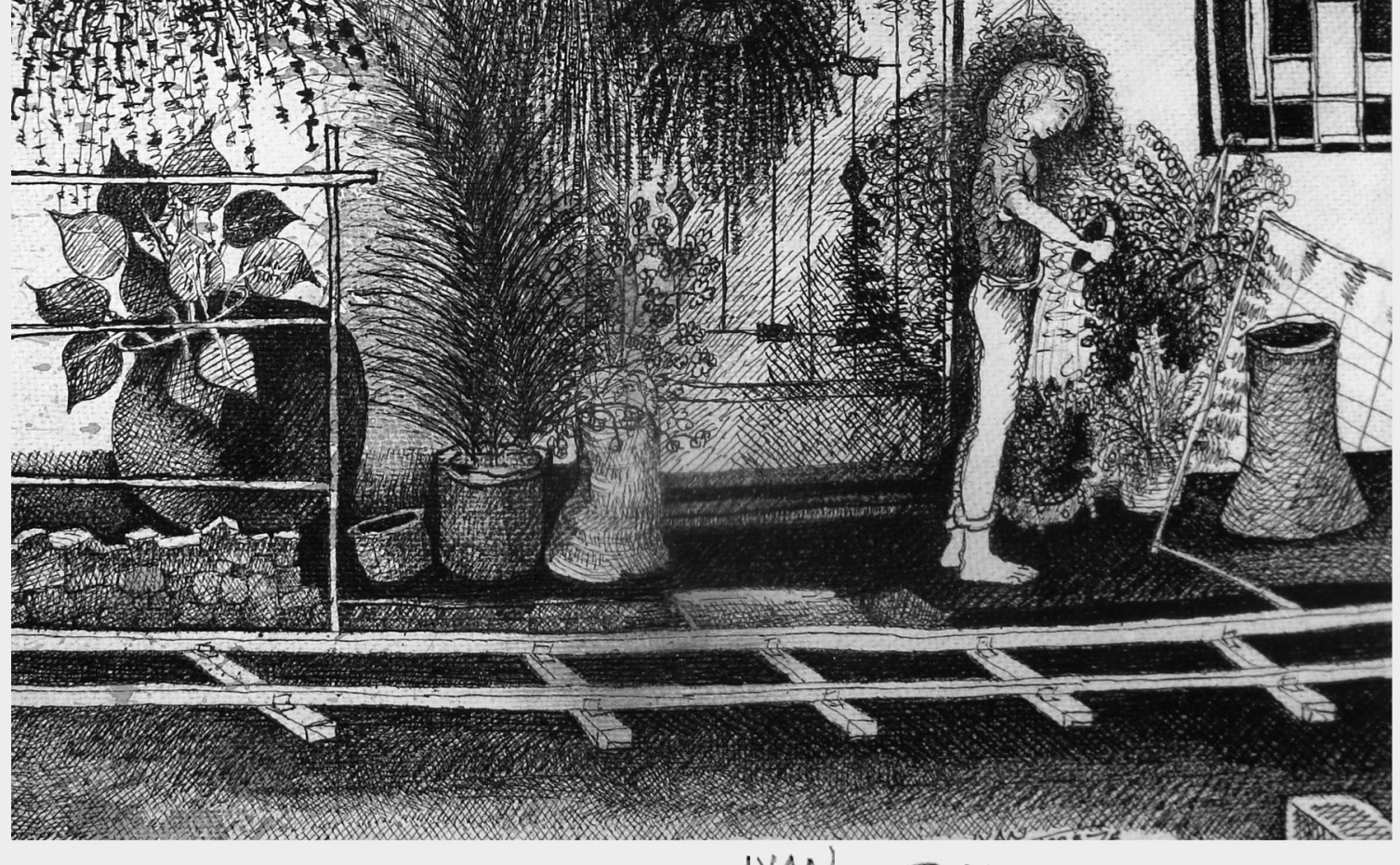

$$
\text { IVAN }
$$

